\title{
WERNER DÜRRSON: KLEIST PARA VETERANOS OU... O PARAÍSO DEFINITIVAMENTE PERDIDO
}

\author{
Elvira Horstmeyer*
}

A

produção em contos (em alemão: Kurzgeschichten) na Alemanha dos anos oitenta, em termos quantitativos, não é grande. Ainda assim segundo o crítico de literatura M. Durzak - a Kurzgeschichte, embora ofuscada pela cultura literária oficial, representa um fenômeno literário de base que, mesmo levando uma existência parcialmente subterrânea, é uma expressão de vitalidade da prosa curta.

O conto que apresentamos aqui é um exemplo de boa qualidade literária; ele comprova o talento de Werner Dürrson (1932), autor até o momento ignorado pelas grandes editoras alemãs de literatura. Em 1983 Kleist para Veteranos recebeu o primeiro prêmio do Kurzgeschichten-Kolloquium, um concurso internacional de contos, promovido desde 1969, em intervalos de dois anos, pela cidade de Amsberg, situada na Renânia do Norte. $O$ conto apareceu em publicação independente do Kurzgeschichten-Kolloquium, a série BE-

\footnotetext{
* Universidade Federal do Paraná
} 
FUNDE. ' A tradução que utilizamos para as citações na seqũência deste trabalho é nossa.

O conto de Werner Dürrson apresenta forma análoga ao famoso ensaio de Heinrich von Kleist Úber das Marionettentheater ${ }^{2}$, escrito em 1810. Em KJeist, um bailarino de ópera dialoga com um curioso sobre a relação existente entre razão e graça ou racionalidade e naturalidade ou consciência e inocência. Os personagens de Kleist valem-se de imagens que, à maneira das parábolas, ilustram uma complexa reflexão filosófica acerca dos destinos do ser humano. No conto de Dürrson, dois espectadores de um show de strip-tease, enquanto comentam a apresentação, fazem citações diretas do tex to kleisteano e claras referências a ele. Dürrson conta uma história, cujo conteúdo trivial transporta - igualmente como parábola - uma continuação e atualização da reflexão filosófica iniciada por Kleist. Na história contada por Dürrson encontramos paralelos com a ficção científica popular da atualidade, onde andróides e criaturas andróginas desafiam nossa imaginação.

O enredo: de passagem por Paris, o narrador lê no "Figaro" um anúncio sobre um "lightshow à l'américaine", ali apostrofado de "simbiose entre a tecnologia e o princípio do prazer". Ele vai ao show e senta-se ao acaso à mesa de outro homem. No início, o show é um espetáculo comum de strip-tease. Depois, a atração principal, a dançarina Marie Jean Crack, desacopla sucessivamente os membros de seu corpo e os lança ao público, onde somem misteriosamente. No final, a bailarina é apenas uma cabeça falante que sobrevoa os espectadores. Estes tentam derrubá-la, atirando nela toda sorte de objetos, mas ela desvia rapidamente dos projéteis. Tudo termina numa pancadaria geral, a polícia interfere e expulsa todos da boate.

A ação tem no estilo narrativo de Dürrson uma correspondência formal. Os parágrafos estão compostos como mosaicos lingüísticos: periodos incompletos, vazios semânticos, o uso parcimonioso de pontos finais, a presença abundante de vírgulas produzem, ao nível da linguagem, um efeito de fragmentação, que espelha a operação de desmonte do corpo da dançarina:

enquanto Marie Jean Crack se levanta com o pénis ereto, um hermafrodita à la mode, sem dúvida, visivelmente bastando-se a si mesmo, exibe agora toda sorte de meias coisas e coisas duplas, de forma alusiva e mesmo assim precisa (nào é cer-

1 HERRING, H. (ed.): Befiunde VII-VIIl. Arnsberg. 1984. p.62-66

2 KLEIST. Heinrich von. Über das Marioneltentheater. Zur Poutik. Reinbek bei Hamburg: Rowohlt. 1964. p.5-12. Para as citaçōes utilizamos a traduçāo de Claudia Cavalcanti. A marquesa d'O e outras estórics. Rio de Janeiro : Imago, 1992 
tamente o ideal do relacionamento humano), antes que ela ou ele - será que estou enxergando bem - com gestos seguros desatarraxar os seios, os dois ao mesmo tempo, um em cada mão, e em seguida atirá-los como discos na escuridão (não se ouve a queda), agora está masculino, só que muito liso, sem pêlos, pelo que consigo ver, na forma é sem dúvida um travesti, Jean Marie Crack, então era esse o ponto, estrela de strip-tease duplamente excitante,. .3

A relação com o texto de Heinrich von Kleist se estabelece no momento em que o narrador e o seu parceiro de mesa iniciam o diálogo. Pensando em voz alta, o narrador comenta que a dançarina "parece estar pendurada por fios", ao que o outro responde, citando literalmente Kleist:

Todo movimento tem um centro de gravidade, é é suficiente dominar esse movimento no interior do corpo; os membros, nada mais que pêndulos, seguem por $\mathrm{si}$; toda vez que o centro de gravidade é acionado em linha reta, os membros deserevem curvas, o movimento toma-se rítmico. ${ }^{4}$

Faremos a seguir um breve excurso ao ensaio de Kleist sobre o Teatro de Marionetes 5 para resumir o pensamento desse famoso poeta sobre a dicotomia razão/graça ou racionalidade/naturalidade ou consciência/inocência. Para este resumo recorremos ao ensaio Das verlorene und wieder zu findende Paradies, de Benno von Wiese. ${ }^{6}$ Esse renomado crítico de literatura faz um estudo sobre o conceito da graça em Schiller, Goethe e Kleist. Na parte dedicada a Kleist, Wiese se detém longamente no texto Über das Marionettentheater, determinando o conceito kleisteano da graça, bem como os paralelos que esse conceito encontra nas obras dos outros dois autores. Wiese detecta analogias entre o pensamento de Schiller e Kleist, comprovando que o clima intelectual do século XIX propiciou reflexões do gênero. Para explicitar a relação entre Kleist e Dürrson, faremos aqui somente um resumo do trecho que Wiese dedica

3 DÜRRSON, op. cit., p.62.

4 DÜRRSON, op. cit., p.62.

5 Op. cit.

6 WIESE, Benno v. Das verlorene und wieder zu findende Paradies. Eine Studie über den Begriff der Anmut bei Goethe, Kleist und Schiller. In SEMBNER, H. (ed.) Berlin, 1967. p.196-220. 
à interpretação do texto Über das Marionettentheater. Restringimo-nos ao essencial para esta análise comparativa.

\section{A utopia kleisteana da recuperação do paraíso}

Ao ser expulso do paraíso, o homem foi privado da graça. ${ }^{7}$ A pós comer da árvore do conhecimento, ingressou no estado da consciência, a qual estabeleceu uma desordem na graça, um desequilíbrio entre graça e razão, fazendo dele um ser cindido entre a verdade e a realidade, entre o Eu e o mundo. Em outras palavras, a consciência, o pensamento, a capacidade de reflexão, são responsáveis pela cisão do homem, estado em que ele se encontra desde a perda do paraíso. O homem pós-paraiso está excluído do campo da graça, da qual conserva apenas uma recordação utópica, enquanto se debate com as tragédias da sua condição temporal.

Entretanto Kleist delineia no seu ensaio uma possibilidade até entāo inédita para a recuperação do paraíso:

Mas o paraíso está trancado e o Querubim, atrás de nós; procisamos dar a volta ao mundo e ver se talvez, por trás, não há outra porta. 8

Na concepção de Kleist, a configuração do mundo é circular. Em algum lugar no futuro, após "dar a volta ao mundo", o homem chegará de novo ao paraíso, mas dessa vez "por trás", isto é, pelo outro lado do círculo. Esse "algum lugar no futuro" será atingido após a passagem do homem por todas as tragédias decorrentes do seu estado de cisão. A condição humana, tendo sido vivida e revivida, chegará a um ponto de esgotamento e então o homem estará de novo no lugar de partida. Encontrar a porta dos fundos do paraíso, porém, não é resultado da vontade ou do esforço ou de um processo de amadurecimento intelectual do homem. A passagem para o que Kleist concebe como segundo paraíso ocorrerá de forma inesperada, repentina, misteriosa.

Na parte final do texto kleisteano lemos:

7 Segundo Benno von Wiese (op. cit.), para Kleist os conceitos de graça, paraíso e inocência são mutuamente correspondentes.

8 KLEIST, op. cit., p.225. 
Dessa maneira, disse eu..., deveríamos comer novamente da árvore do conhecimento, para voltarmos ao estado de inocência? Certamente, respondeu. Este é o último capítulo da história do mundo. 9

É preciso entender que "comer novamente da árvore do conhecimento" não significa negar o conhecimento e retornar ao estado de inocência anterior. Tendo passado pelo mundo, isto é, pelo estado da consciência, no seu reingresso no paraíso, o homem não perderá o conhecimento. Ele recuperará a graça, integrando-a à consciência.

O homem retornará à "inocência" através do conhecimento e da consciência, isto é, tendo vivido a cisão até os scus extremos máximos, cle a superará repentina e inesperadamente. ${ }^{10}$

O segundo paraíso de Kleist corresponde a um estado de expansão máxima da consciência, à superação das dicotomias existenciais, e ele se situa além do trágico e de todas as categorias morais. No segundo paraíso, o homem terá atingido o que o autor chama de "consciência infinita".

Vejamos o que Kleist entende por "consciência infinita": O homem tem, na sua condição temporal, duas possibilidades de preconceber o que é a graça; elas estão na marionete e no deus. ${ }^{11}$

A marionete possui graça nos momentos em que o operador transporta a consciência dele para o centro de gravidade da boneca, fazendo-a dançar. Essa imagem evoca o pensamento (que na época de Kleist já não era novo) de um deus dirigindo os movimentos do homem. Nesse caso, o deus é que seria o dançarino, cuja alma, colocada em harmonia com o centro de gravidade do homem, estaria conduzindo os movimentos deste. Entretanto, essa harmonia entre o homem e o deus só é possível através do inconsciente humano, já que a expulsão do paraíso lançou o homem no estado da consciência, onde ele está sozinho, vivendo as conseqüências de suas próprias decisões. A tragédia, o pecado, a reflexão não fazem parte de um teatro de marionetes dirigido pelo deus. $\mathrm{O}$ homem manipulado pelo deus existiria em sua própria e mais autêntica

9 KLEIST, op. cit., p.228.

10 WIESE, op. cit., 210. A tradução é nossa.

11 KLEIST refere-se à divindade sempre como "um deus"ou "o deus", o que leva Wiese a supor que o autor fez desse deus uma projeçāo utópica do homem. 
verdade somente quando estivesse em consonância plena com o seu mundo interno, executando apenas os movimentos ditados pelo manipulador divino, cuja "alma" se encontraria no seu centro de gravidade. Os dois aspectos não estão em contradição, significam a mesma constelação vista por dois prismas. $O$ operador, ao mesmo tempo em que conduz a dança da marionete, lhe confere total liberdade de ser, e essa liberdade é vivida como tal pela boneca. ${ }^{12}$

Mas Kleist projeta também uma marionete utópica, totalmente livre do seu manipulador, e a sua dança se dá inteiramente no campo das forças mecânicas. Ela não seria destituída de alma; seria antigrave, qualidade que faria dela a marionete mecânica ideal, um ser em harmonia total e permanente consigo mesmo, com o seu próprio centro de gravidade. A lei que conduz sua dança está nela mesma. Sua liberdade não seria a da escolha e sim a liberdade de ser. A perfeição mecânica da marionete, sua dança auto-impulsionada, é uma parábola para o estado de "consciência infinita", que o homem alcançará quando reencontrar o paraíso.

Kleist concebe o segundo paraíso com o pressuposto de que também o deus tem graça. A graça do deus é igual à consciência infinita: ela não encontra obstáculos diante de si, encontra sempre e somente a si mesma, ou seja, consciència e realidade sāo permanentemente idênticas. Na utopia futurista de Kleist, ao encontrar a porta dos fundos do paraíso, o homem ingressará no estado da consciència infinita. Ele existirá e terá ao mesmo tempo o conhecimento infinito de sua existência; nessa identidade total do homem consigo mesmo não haverá mais cisāo, o que equivale a dizer que "no último capítulo da história do mundo" o homem será um deus.

Encerramos aqui este excurso, com o que retornamos ao conto Kleist para Veteranos ou Falsa Rebelião dos Sentimentos. Vejamos como Werner Dürrson desenvolve a filosofia kleisteana. Esse conto foi analisado de forma elucidativa por Manfred Durzak, em seu livro Die Kunst der Kurzgeschichte ${ }^{13}$, cujas conclusōes incluímos parcialmente neste estudo.

12 O campo de significados em que Wiese situa o conceito da graça, conforme ele ocorre no texto de Kleist, abrangem: leveza, alma, dança, calma no movimento, antigravidade, equilibrio, segurança. Como a maioria desses conceitos se aplicam à Estética, inferimos que a graça pode ser vislumbrada nas obras de ante. Entre o artista e sua obra existiria relação análoga à descrita acima entre deus' - manipulador e homem/marionete. Mas o conceito da graça nāo se esgota no campo da Estética.

13 DURZAK, Manfred. Die Kunst der Kurzgeschichte. Zur Theorie und Geschichte der deutschen Kurzgeschichte. München: Wilhelm Fink, 1989. p.325-31 


\section{Kleist para Veteranos ou Falsa Rebelião dos Sentimentos}

Pelos comentários dos personagens ao show da dançarina Marie Jean Crack percebemos que eles conhecem a utopia concebida por Kleist. O narrador está profundamente imbuído desse ideal, enquanto o outro personagem declara a obsolescência dele e apresenta outra reflexão, ao mesmo tempo intrigante e assustadora.

O narrador sente falta da naturalidade na dança de Marie Jean Crack, e o outro tenta explicar:

Essa forma de expressão, o controle sobre os membros, parece artificial porque é na essência calculado, ou seja, é potência intelectual transmitida ao corpo. ${ }^{14}$

Entretanto, na continuação do show, essa "potência intelectual " desintegra, destrói o corpo, começando pela eliminação da diferença entre os sexos:

...enquanto Marie Jean Crack se levanta com o pênis ereto, um hermafrodita à la mode,...visivelmente bastando-se a si mesmo... antes que ela ou ele com gestos seguros desatarraxar os seios...e atirá-los como discos na escuridão, agora está masculino ... 15

A dançarina - Marie Jean ou Jean Marie, homem e mulher ao mesmo tempo - continua desacoplando as partes do seu corpo, jogando-os para longe, como se fossem supérfluos, até quando resta apenas a sua cabeça, suspensa no espaço, e ele/ela repete sem parar "Me chamem Robbie". O narrador está incrédulo e estupefato, enquanto o seu parceiro de mesa, com espantosa natualidade e aparentando familiaridade com o assunto, dá uma explicação pragmática ao fenômeno:

A tecnologia, fato inquestionável para ele, era a continuação lógica da natureza. ... Esses reversíveis processos de desarticulação crakianos ... eram apenas e nada mais que naturais. Só que em nivel muito superior: ver/ouvir/sentir, tudo isso havia se transformado no pensamento dessas novas criaturas ... ${ }^{16}$

14 DÜRRSON, op. cit, p.63.

15 lbid

16 Ibid., p.65. 
O narrador tem uma explosão de revolta:

... eu grito na cara do sabichão que o meu corpo, mesmo sendo de ontem. com toda a sua suscetibilidade e debilidade, com toda a dor de cabeça, dor de barriga, taquicardia, ouviu bem?, apesar das varizes ... do reumatismo e até da impotência, esse corpo me é caro, caro demais, entendeu meu caro senhor?, ... 17

O personagem exprime assim a sua "falsa rebelião", falsa porque inútil, atrasada em relação a uma evolução que o interlocutor aceita com serenidade como um fato dado, irreversível. O narrador faz o papel do herói romântico, lutando nesse caso pela preservação de um corpo humano decrépito, já que o descreve com suas qualidades menos apresentáveis. É a revolta do idealista, que no contexto se mostra grotesca.

Mas é ele de novo quem toca na questão central, insistindo em saber dos atributos que, pelo menos até Kleist, ainda eram essência inalienável do ser humano:

... me pergunto, enquanto há tempo, onde estará nela o aparelho sensitivo, o Eu, sua sensação corpórea, para não falar em dor/alegria/prazer; e mais uma vez, se tudo isso era magia, brincandeira

Não é brincadeira. A visão de futuro que Dürrson delineia e com a qual atualiza a de Kleist é assombrosa. Se Kleist via para o homem a possibilidade de restabelecimento da harmonia entre razão e graça, Dürrson, menos de duzentos anos depois, declara que o homem está em vias de perder os últimos vislumbres de graça que lhe restam, está prestes a ser substituído pela máquina:

E a estética, a graça?

Questão de perfeição. - Você se surpreende com a nossa tecnologia que já substituiu tudo, desde a máquina de cortar grama, passando pelo automóvel e pelas máquinas voadoras, que já substituiu até os animais, com exceçāo do gado de corte,

17 DÜRRSON. op. cit.. p.65.

18 Ibid 
... se surpreende com essa tecnologia estar tentando agora elevar à perfeição o conceito de homem? O mais primário dos robôs seria mau aluno se com o tempo não superasse o mestre. A obra-prima da criação, digo. Não, obra-prima não, nave espacial talvez. O espírito não desceu do céu, vamos ter de lançá-lo para o alto. ${ }^{19}$

A tecnologia já nos apresentou fatos e perspectivas, como o transplante de órgãos e a manipulação dos gens, que poderiam indicar a direção para onde caminha a evolução da espécie "homem", a decantada obra-prima da criação, parâmetro que durante séculos de filosofia orientou todas as visões futuristas. O conceito kleisteano de perfeição - o homem quando integrasse a graça ao conhecimento - $\hat{e}$ substituído pela visão grotesca das criaturas robotizadas, dos homens-máquinas, que a evolução tecnológica nos permite imaginar.

E na afirmação "o espírito não desceu do céu, vamos ter de lançá-lo para o alto" evocamos imediatamente o Espírito Santo, que após a ascensão do filho de Deus assumiu junto ao homem a função de Consolador. Estaria aqui uma assustadora negação da bela imagem da marionete que dança com graça, porque o manipulador lhe empresta sua alma? Então o manipulador é uma ilusão e a marionete não é a antevisão do estado de graça a ser recuperado pelo homem. E a afirmação do freqüentador de shows eróticos teria de ser entendida como uma declaração da inexistência do deus. E é no mínimo cínica a sugestão de que uma nave espacial deveria finalmente lançar para o alto o que esteve lá unicamente como produto de nossa imaginação.

No final do conto, o narrador dirige ao seu parceiro de mesa a mesma pergunta que, no texto kleisteano, o curioso fizera ao bailarino de ópera. Porém o narrador de Dürrson introduz na citação a palavra "novo":

Nesse caso ... teríamos de comer novamente da árvore do conhe cimento para cair num novo estado de inocência?

Tarde demais, grita ele, além, na noite luminosa, mas Crack pode fazer isso por você. ${ }^{20}$

O trecho sugere que não há nada de novo a ser imaginado em relação ao paraíso. Pelo contrário. A idéia de paraíso se tornou tão obsoleta quanto a

19 DÜRRSON, op. cit., p.66.

20 Ibid. 
idéia do deus. Se a utopia do paraíso se dissolveu no tempo, podemos inferir que também a história bíblica da criação está ultrapassada. E se o homem não pode mais sonhar com a volta ao paraíso, o que lhe resta? A solução estaria na lacônica resposta do personagem "Crack pode fazer isso por você"? Voltaremos a essa afirmação no final deste trabalho.

Mas Dürrson faz referência a outro evento bíblico de significação central na história da criação, o dia do Juízo Final:

Talvez os outros também esperassem, como eu, que Crack pelo menos chamasse os seus membros de volta juntasse os seus pedaços ... como no dia do Juízo Final; ele poderia ter se transmutado, e o jogo combinatório de dois ou mais Cracks teria sido $\ldots$ mais interessante do que esse resto de cabeça walkietalkic. 21

A chamada dos membros para reintegraçāo com a cabeça, como no dia do Juizo Final, não acontece. Os membros se dissolvem no ar, e a sua desintegração parece ser apenas um fato corriqueiro. A visão que Dürrson nos apresenta para o futuro do homem é a imagem assustadora do intelecto autônomo, absolutizado, sem alma, sem transcendentalidade.

Segundo essa visão, o homem contemporâneo, quando olha para a sua história pregressa, constata a inconsistência de todas as crenças fundadas no pressuposto de sua origem divina, constata a obsolescência da história da criação e portanto da união entre corpo e espírito. E como o estágio atual da evolução tecnológica indica que nos encontramos num caminho sem retorno, ao olhar para o futuro, o homem antevé a sua progressiva desumanização, que abrange a perda da moralidade. No universo da concepção de Dürrson o único consolo estaria embutido na insinuação do personagem acima citada "Tarde demais. Mas Crack pode fazer isso por vocên ${ }^{n}$. É tarde demais para sonhar com a volta ao paraíso, mas Crack se apresenta como um novo consolador. Dentre os muitos sentidos da palavra "Crack" transcrevemos alguns, que poderiam indicar o que o personagem está sugerindo:

Crack - recordista nos esportes; o melhor cavalo de um plantel; droga sintética, contendo cocaína. ${ }^{22}$

21 DÜRRSON, op. cit.. p.65.

22 DUDEN. Deutsches Universalwörterbuch. 1989. p.310. A traduçāo é nossa. 


\section{RESUMO}

O presente trabalho procura estabelecer e analisar a relação entrc o conto de Wemer Dürrson Kleist para Veteranos ou Falsa Rebeliao dos Sentimentos (1983) e o texto de Heinrich von Kleist Über das Marionettentheater (1810), principalmente no que diz respeito à reflexão filosófica sobre o futuro do homem, iniciada por Kleist e continuada por Dürrson.

\section{ZUSAMMENFASSUNG}

Diese Arbeit versucht, die Verbindung zwischen der Kurzgeschichte von Werner Dürrson Kleist für Fortgeschrittene oder Falscher Aufstand der Gefühle (1983) und dem Aufsatz von Heinrich von Kleist Über das Marionettentheater (1810), herzustellen und zu analysieren, besonders in Bezug auf die von Kleist begonnene und von Dürrson weitergeführte philosophische Reflexion über die Zukunft des Menschen.

Palavras-chave: Kleist e o Teatro de Marionetes, O Futuro da Humanidade, Conto dos Anos 80, Fiç̧ão Alemã, Werner Dürrson.

\section{REFERÊNCIAS BIBLIOGRÁFICAS}

DUDEN. Deutsches Universalwörterbuch. Mannheim : Dudenverlag, 1989, p. 310.

DÜRRSON, W. Kleist fïr Fortgeschrittene oder Falscher Aufstand der Gefühle. In: HERRING, H. (ed) Befunde VIl-VIII. Amsberg: 1984, p. 62-6.

DURZAK, M. Die Kunst der Kurzgeschichte. Zur Theorie und Geschichte der deutschen Kurzgeschichte. München : Wilhelm Fink, 1989, p. 325-31.

KLEIST, H. von A Marquesa d'O e outras Estórias. Tradução: Claudia Cavalcanti. Rio de Janciro : Imago, 1992.

KLEIST, H. won Über das Marionettentheater. Reinbek bei Hamburg : Rowohlt, 1964, p. 5-12.

WIESE, B. von Das verlorene und wieder zu findende Paradies. Eine Studie über den Begriff der Annut bei Goethe, Kleist und Schiller. In: SEMBNER, H. (ed.) Berlin: 1967, p. 196-220. 